\title{
Students' perceptions of the 'With Industrial Experience' degree pathway in electrical and electronic engineering
}

\author{
Konstantinos Kopsidas, ${ }^{1}$ Maria Pampaka ${ }^{2}$ and Sheila Knowles ${ }^{1}$ \\ ${ }^{1}$ School of Electrical and Electronic Engineering, The University of Manchester, Manchester, \\ UK \\ ${ }^{2}$ School of Education, The University of Manchester, Manchester, UK \\ E-mail:k.kopsidas@manchester.ac.uk
}

\begin{abstract}
This paper presents the 'With Industrial Experience' programme offered as an option to undergraduate students in the School of Electrical and Electronic Engineering at the University of Manchester, usually between their second and third year of study. Our focus is on the students' perceptions of the programme drawing on eight interviews with students who had already completed the course. By highlighting students' view of the benefits and also limitations of the programme we hope to inform our immediate plans for improvement of the course as well as the practice of others with similar programmes, globally.
\end{abstract}

Keywords career orientation; employability; industrial experience; students' perceptions

This paper presents a case study from the School of Electrical and Electronic Engineering (EEE) at The University of Manchester, about the 'With Industrial Experience' (WIE) programme. Here, we present the implications from our experience in order to inform international practice. The programme falls under broader international attempts to increase the number of students in Science, Technology, Engineering and Mathematics (STEM) courses in Higher Education (HE) and particular efforts to increase students' transferable skills and consequently their employability. Such efforts run in parallel with other colleagues' efforts (as in Ref. 1) to respond to employers' concerns that electrical engineering graduates, although very knowledgeable technically, have difficulty in problem solving and translating theory into practice. This seems to be a global trend, as noted by others. ${ }^{2}$ This paper aims to present the students' perspective on this programme and their experience during their industrial placements, drawing on interviews with students who had already completed the course. Before presenting the followed methodology and the main results, a brief overview of the programme is given.

\section{Overview of the WIE programme}

The 'With Industrial Experience' (WIE) programme for students of the School of EEE is a year-long industrial placement of students after completion of their second or third year in the three- or four-year Engineering degrees, respectively. In particular, undergraduate courses of Electrical and Electronic Engineering, Electronic Engineering, and Mechatronic Engineering (all offered as three- or four-year degrees) can be combined with a year's industrial placement to make a four- or five-year 
'WIE' course. The aim of the programme is to give students a valuable insight into the 'world of work', vastly increasing their chances of employability and generally to give them a much more mature approach to their studies upon their return to university. As stated in the Handbook of the programme:

'The school is happy to encourage these programmes because they provide students with a number of benefits, such as experience of applying the knowledge gained in two or more years at University to real-world situations. It is also usual that students obtain many transferable skills that cannot be taught as part of the degree curriculum. Students who have spent time in industry often return with a much clearer idea of the way they see their career progressing, and are highly motivated during the remaining years of study.'

Students are eligible for the programme if they achieve above 55\% during the second year. The successful completion of this programme involves two academic tutor visits during the year, submission of a final report and a presentation at the end.

\section{Review of similar efforts and relevant findings}

Programmes such as our WIE fall within the category of 'practicum' which, according to Ref. 3, 'constitutes an integral part of many professional courses in HE; and is manifest in several different forms depending on the discipline: field experience, cooperative education, sandwich programs, internships, clerkships, clinical practicum and the like' (p. 355). Such attempts are also relevant to efforts towards cooperative education which sees students taught through both formal lectures within their universities and placements with appropriate industrial partners.

There have also been some research studies on these programmes, and on various aspects of their effectiveness. One interesting topic involves the relationship between industrial experience and students' performance. The conclusions of the main studies on this still remain controversial: On the one hand, a longitudinal study of engineering graduates from the University of Leicester found evidence for a positive relationship between placement and higher final degree results. ${ }^{4}$ On the other, some scholars have found that placement students do better because they are better students to start with. Their results 'highlight that it is not merely doing a placement that matters, but a successful placement adds significantly to subsequent performance' (p. 1). ${ }^{5}$

Other studies focused on attitudes. The authors of Ref. 6, for instance, surveyed the opinions of staff, industrial partners and current and past students taking part in 'sandwich' courses in Hong Kong Polytechnic. Others explored the attitudes of placement students in terms of their learning outcomes and future employment aspirations as well as the role of work-integrated learning in developing professionalism and students' professional identity. ${ }^{7.8}$

Finally, in another national case study from London, ${ }^{9}$ researchers found that their optional module (i.e. work placement for professional experience) develops the capabilities and skills of students and enables them to become aware of the culture and structure of a working environment. 
In our case, despite all the reported benefits for students, there has been noticeably poor take-up of the programme in recent years, and further efforts are now in place to reverse that trend. This involves revising the structure of the course in addition to expanding its marketing, as will be discussed below. However, in order to make informed choices about revisions it was thought essential to systematically analyse students' perceptions about the course first. Given the small numbers of participants the most efficient way to elicit such information was semi-structured interviews. The main question we aim to amass a response to here is: 'To what extent is the WIE programme successful in achieving the main expected learning and attitudinal outcomes, of:

(a) application of knowledge gained at university to real-world situations,

(b) increasing transferable skills,

(c) helping students to define their career aspirations, and

(d) increasing graduates employability?'.

Furthermore, we also aim to highlight the main benefits of such a programme, as well as the experience limitations from the students' perspective, in order to inform improvement of future delivery.

\section{Methodology}

For this paper we draw on qualitative data to provide evidence for the perceptions of students about the WIE programme, in regard to the achieved benefits and also perceived limitations, to inform improvement of service provision for the future. In particular, we draw on eight semi-structured interviews conducted with students who completed their placement during the previous academic year (2011-2012). The interviews were carried out by the authors using an interview schedule which included a list of questions and prompts to promote discussion under the four themes presented in Table 1.

TABLE 1 The main themes for the interviews

\begin{tabular}{ll}
\hline Theme & Questions/Prompts \\
\hline Students' background & Reasons for choosing the particular degree \\
& Reasons for doing WIE / particular placement \\
& Expectations and how they were realised \\
& Their role in placement (example of project) \\
The industrial experience & Most useful \\
& Relevance to university courses from before (example) \\
Reports for WIE & Usefulness, how they influenced university coursework, limitations \\
Experience at university after & Relevance of WIE with courses at university after \\
WIE & Effect on particular courses (example) \\
& Effect on career choices \\
& Limitations and suggestions for improvement \\
\end{tabular}


TABLE 2 Basic information about interviewees

\begin{tabular}{lll}
\hline Pseudonym & Course - Year & Details \\
\hline Student 1 & MEng Electrical and Electronic Engineering & Chose WIE from start \\
Student 2 & MEng Electrical and Electronic Engineering & Now in $3^{\text {rd }}$ year of study \\
Student 3 & MEng Electronic Systems Engineering - now & WIE between 3rd and $4^{\text {th }}$ years \\
& Electronic Engineering & \\
Student 4 & MEng Electrical and Electronic Engineering & WIE between 3rd and $4^{\text {th }}$ years \\
Student 5 & MEng Electrical and Electronic Engineering & Now in $3^{\text {rd }}$ year of study Female \\
Student 6 & MEng Mechatronic Engineering & Chose WIE from start \\
Student 7 & MEng Electrical and Electronic Engineering & Chose WIE from start \\
Student 8 & MEng Electrical and Electronic Engineering & \\
\hline
\end{tabular}

Interviews lasted for about 30 minutes and were audio-recorded, and then transcribed. Some background information about the 8 students who were interviewed is summarised in Table 2. It should be noted that pseudonyms are used for the participants and the companies are not mentioned, to preserve anonymity.

Thematic analysis was then performed on the transcripts: results are summarised under broader groups and example quotes from the interviews are presented to justify the main points.

\section{Results}

The main results will be summarised under individual themes.

\section{Theme 1: Students' reasons for doing WIE}

A first point to make here is in regard to the decision to join this programme: for some students (as also shown in Table 2) this comes at the beginning of their degree, whereas others make up their mind later on their courses. Some were influenced by university staff or family members. Others, like Student 3, were influenced by a fellow-student's experience: 'It was really just that experience having someone from a company to come in and talk to them that got me interested'.

Three main points were also raised regarding the actual reasoning behind this choice. The first involves integration of theory with practice, or 'grounding' as Student 1 mentioned: 'you learn a lot of theory here. I wanted to know how you apply that and which bits do you actually apply'. Similarly, Student 7 said: 'I suppose I wanted the experience that goes with the theory'. The second reason had to do with knowing and maybe narrowing down students' options (and careers) within their rather broad degrees:

'For me it was to go and work in a sector and I would know whether or not I liked the sector. It would then help me to choose where my career would be.' (Student 1)

'to narrow down choices and options' (Student 4) 
Finally, the most commonly reported reason had to do with employability:

'Essentially your employees need experience. If I have experience before graduating ... I'd have a higher chance of getting a job after graduating which turned out to be correct' (Student 2)

'I thought it was a good experience with having a year in industry on your cv a great plus' (Student 6)

'It would improve my chances of getting a job after' (Student 8).

Theme 2: Students' expectations from the course and their realisation

Apparently students joined the programme with varied expectations, but it seems that the majority of them were positive about the outcome. Students can be divided into two groups based on their anxieties before their placements: those who were concerned that the job would be highly demanding and those who were concerned that they would be treated 'simply as students'. Student 2 gives a good example of the first group:

'I had no idea what I was going to do - I was scared they might throw me in the deep end but I was unsure of the responsibilities they would give me. I was not really expecting much but it turned out to be very good, they understood that I did not have any experience they give you a small thing to do, they get someone to show you how it's done and they eventually give you more and more responsibility and I think towards the end (I don't usually like to brag) but the work I was doing was actually quite close to what an experienced engineer would be doing'.

In comparison, Student 4 went into the programme with rather different expectations; however, he was equally satisfied at the end:

'To be honest I thought that I would be getting all the jobs that real engineers didn't want to do. Like if I was running a business I wouldn't hire a student to do half the stuff that I got to do but I would hire them to do the simple stuff, so the proper engineers can concentrate on the more difficult stuff. I was one of the design engineers. I made 2 instruments. One instrument, 200 have been sold already, completely designed by me, that's an electronic box to the wiring to the instruction manual, the label and everything designed by me'.

Some other conflicts between students' expectations and their realisation (or not) appeared at different levels. Student 8, for example, 'expected to work in the power station' but instead he 'worked in an office'. Even with this change of plans he found the experience 'still good because I know how the corporate world works for the future. I would like to start my career in engineering, hands on, actually applying what I learned here'. The most negative example of conflict between expectations and reality in placement was probably given by Student 6, who was disappointed by the management of the placement from the company's site: 'it was like we were 'guinea pigs'. This was the first time they had done internships and they weren't 
quite sure what to do with us so most of the projects I have done were based upon my own initiative'. Even though this was a minority experience, it should be taken forward to feedback for improving the experience.

Theme 3: Students' perception of what benefits they got from the experience In this section we look into the reported benefits of the experience from students' perspective, as they responded to the question 'what did you find most useful from this experience?' Their responses can be grouped again into broader categories:

\section{Position/role specific benefits}

'For me it was technical sales because my objective going into Company X working for a year in industry was to learn both technically and to improve my technical knowledge for university and the rest of my degree, but then also I wanted to learn commercial skills to prepare me for the outside world. And I think a combination of these would give me an all-round experience and I think that technical sales offered me this' (Student 5)

\section{Employability}

For some students, like Student 6, the most important aspect of WIE is the fact that 'it is quite useful on my cv'.

\section{Communication and project management skills}

These were mentioned either in relation to the effect of the WIE programme on the fourth-year project or as general transferable skills: 'soft skills working with people in many different departments, managing my time, exposure to a real job', and 'the experience of communicating with different people from different disciplines'.

\section{Maturity and responsibility}

For some others, the major reported benefit of such experience is the effect it had in their personal growth. As Student 2 stated:

'It is very different from doing projects at university because the motivation is different because you want to learn from it - you want to pass with it for good grades. In industry someone gives you work to do and if you don't do it then someone is losing money and from that point of view you actually learn to take real responsibility. I would say that taking responsibility is actually up there in my useful things from my industrial experience'.

Theme 4: Relevance to university courses (before and after) - examples Another important aspect of WIE is its integration with students' university courses: those attended both before and after their industrial experience. Apparently, the courses/modules students consider relevant are related to the sector/area of the particular industry they joined, so it is not productive to compare courses before the WIE. Moreover, students found the first two years of their degrees very broad in general. As a student reported 'if I had gone after the third year I would have had 
more knowledge but because after second year we didn't really cover enough technical content, we learned the $A B C$ of engineering.' It may be informative, however, to list the modules mentioned by students as relevant or informative for their placement. Students in sum mentioned the following as useful for their placement:

- Sensors and Analogue Circuits

- Systems Engineering

- Systems Machines

- Theory of Control Systems

- Software engineering

- Microcontroller project

- Micro-computer Engineering

- Electrical Systems Engineering

- Transmission Lines

Student 1 also provided a useful example of how they applied their knowledge from Sensors in their placement:

'As I happened to be the only Electrical Engineer, both other guys were Mechanical Engineers. So we had to monitor the current and voltage and I developed relatively cheap sensors, I developed the circuit to modify the signals so we could then meet them into our logger or whatever we were using at the time'.

The integration of learning does not seem to be one way, as reported by students. For some the industrial experience also provided knowledge and learning:

'This particular company, not only have they helped me bolt on the skills I already had but they also introduced fundamentals, like technical skills to me, for example Digital Mobiles. I had no idea about anything to do with that whatsoever because it was a brand new third-year module. We hadn't covered any of it before so it was really good that they introduced that because they knew that one of my keen interests, was that I wanted to make sure I was fully prepared to go into my third year. I then applied the fundamentals I had learnt at Company X and then applied it at the university'. (Student 5)

When back to university, after their placement, students seem to be more reflective now about what they learn and the relevance of their courses with 'real jobs'. For some, module choices are even guided by this experience, as for Student 1:

'At the end of my year in industry they offered me a job which meant that I could tailor my courses in my final year to match the job.... Two of my modules this year are Design of Electric Machines and Advanced Power Electronics which will then specifically be able to help my job when I go back ... so for me I wouldn't necessarily have chosen those if I had not done the year in industry. ... They are a little bit tedious and very difficult courses, not many people select them.' 
Some students also reported that their experience in industry helped their understanding of modules they are now attending at university:

'I did Control Systems I before going on placement and now I'm doing Control Systems II which is making much more sense to me.' (Student 2)

'Digital Mobile Communications: I learnt a bit about all this stuff and when I was doing the module it was much easier because I knew... It definitely helped, I think I was able to visualise what the academic was talking about more easily than if I had just been introduced to it.' (Student 6)

Students reported benefits that go beyond particular modules and the apparent effect on their final year and team projects. The quotations below are self-explanatory:

'You seem get a feel - when you are in the lectures they tell why $x$ goes to $z$; when you see something in practice you have a better understanding for it and I think that's why they have labs as well because I always found that after doing a lab for a module I understood what is going on. It makes things fall into place.' (Student 2)

'Time management everything it is actually like real life... Before I was undecided between the MSc and MEng but now I am really glad I chose the MEng course because I could see the relationship the course and real life.... It is very exciting to get a project that is actually applicable in real life because you are building something that can be used somewhere.' (Student 8)

\section{Theme 5: Relevance and usefulness of reports}

Relevant to the aforementioned benefits are students' perceptions about the relevance and usefulness of the reports they had to produce. The majority found these useful. On the positive side were noted the following:

- Good for reflection

- The presentation [gave students' self-confidence]

- Report-writing skills, communication skills

- It pushed us to log everything that we have done and what we have learnt which is highly important.

- It is just useful for the future like now, when I'm applying for any job I just refer to my reports because it just summarises all I have done throughout the year

Some problematic aspects were also reported:

- Time and overlapping deadlines [they would like flexibility with deadlines lenient]

- Trying to fit it in with the workload you have.

- The length - it should be let the student decide - should be sensible.

- They would prefer to write official reports [compared to academic] 
The last point was also raised and supported by a few students and should be noted for future consideration:

'I think a combination of the university reports as well as the company reports, I had to write technical reports at Company X. I think a combination has really helped with report writing in university.' (Student 5)

'The main thing that helped me was writing reports at work because it's a different style of writing. At uni you write to prove that you know something to get marks, at work you just want to explain to someone as quickly as possible how it works and how to carry on with it. That was probably the most useful experience...' (Student 3)

'In university we are required to write academic reports and there's a relatively big difference between an academic report and an industrial one and it would have been nice to have learnt a bit more on how I should write a report for industry.' (Student 1)

\section{Theme 6: Improvement of performance after WIE?}

Even though at the time of the interviews students were not aware of their first semester grades, most of them expressed a perceived improvement in their performance after their industrial placement:

'One of the reasons I was very happy to go into industry, by the end of the third year I had completely lost motivation. It was just all theory and boring I didn't see how it applied. Coming back after a year in industry I realise now where it is all going ... and for my fourth-year project I have clear goals on what I want to achieve and I have a bit more experience than those around me so I am now project manager and I can see things better. My fourth-year project is benefitting, my motivation is benefitting and I have a clearer view of what is happening this year.' (Student 1)

'I think second year my grades were falling down, lack of motivation or whatever, I don't know. But coming back now I felt that I have worked harder this semester and I think again I am expecting better grades. It's given me enthusiasm for the subject. I can do it with more interest now.' (Student 2)

'Don't know yet [about grades] but time management skills much better and having managed time better results should be a level above those I had in second and third years.' (Student 3)

'I've always said that since I've done my year in industry I just know things. I'm doing my fourth-year project now and it is just crazy how much you've learnt during that year.' (Student 4)

'I believe I was a lot more confident in the exams and my thinking has completely changed... For group reports for our modules, I've had good feedback and also for our individual project. We had a progress report written last year, which was 
quite successful. I can compare to my report writing in the second year also. There is a good $10 \%$ difference.' (Student 5)

'I don't know if I will improve my grades but it has helped me to appreciate what I am being taught more than improve my technical ability.' (Student 7)

Most of the improvement was manifested as a change in motivation, which is equally important for students' progression, or a direct effect on actual grades from feedback they received. An exception to the above perceived improvements was a student's reported difficulties related to his return to academic study:

'... I took a year off without doing any significant technical work so when I came back, I think for the semester I found it hard to start studying again and just getting yourself into the routine.' (Student 6)

\section{Theme 7: Career effect}

In order to evaluate the effect of the WIE programme on students' career prospects and choices, the interviewees were asked to comment on any changes in their plans because of the experience. It should be noted that at least two of the students already got offers from the industries they had the experience with. For others, that year helped define their career prospects, when before they were almost clueless about what they wanted to do. Student 3, for example mentioned:

'I have a better idea of where I want to be in the future because of my exposure to industry. I wouldn't say the course has necessarily shaped where I want to go.... maybe not the field I want to go into, whereas the year in industry has helped give me an idea what I want from the work.' (Student 3)

For some of those who had some idea about potential careers, the industrial experience made them see some possibly better prospects than their original choices:

'I initially wanted to get into infotech and gadgets. I was a gadget man....Actually I kind of fell into electric vehicles. I worked for a small company in my second year and they were trying to design an electric van. I did a bit of work on that and because of that I got pushed into hybrids. I really enjoy it now, I think it is the stepping stone for future technologies.' (Student 1)

'When I started the degree I really wanted to go into Power and Energy Transmission and since I've been doing Control after discussion with friends some experienced people in this industry it is more interesting than I thought ... But I found this field really interested me as well so you could say that it did change. From Power to Control.' (Student 2)

'... when I started the course I was going towards something more like electrical machines but now I'm going more towards power, power economics, transmission, plant operation. I've changed a bit but now because it's all related. It is the future.' (Student 8) 
Theme 8: Recommendations for prospective students and feedback for improvement

Students were asked to reflect on their experiences and provide some feedback as to how the programme could be improved, as well as what they would advise fellow students regarding the programme. Their suggestions are summarised below:

- Better communication between industries and university could resolve some 'administrative' hustles when in placement. This also relates to a suggestion for 'more structured' programme.

- Making the reports a bit of a learning experience to help teach students how to write for industry would be very beneficial.

- More help by the university with writing applications [one also mentioned that some companies 'have ridiculously long applications, which is off putting'

- More flexibility with deadlines

- More feedback (about the reports and submitted documents)

The final point seemed to have been dealt with to some extent since another student already observed a difference:

I can see the change since I was first here because I am getting more feedback. Everyone wants more feedback to actually know what and where you went wrong. Academics are easily approachable and you can talk to them about anything.

Others also valued the minimal intervention from the university:

Minimal intervention from the university, visits every now and then and reports every 3 months gives you a chance to feel like an employee of the company rather than a student on placement because you are not always being checked up upon by an academic. You have freedom but also contact with the university if you need it.

Overall, students would recommend such a programme to others. Student 2 for example mentioned:

I could definitely advise the students to do it. It is something that is really job security; it develops in so many other ways as well. Personal and Professional Development. When you are at university you are only dealing with other students, when you are at work you are dealing with more experienced and mature people and so it's different. Going from an educational environment to a real world environment. And when you bring that back into the educational environment you feel the difference.

A student indirectly commented on the cost and summarised his views:

'it upsets me to hear others criticise the programme because of the cost. I do see the value in it. I could have asked for more support if I had needed more....It would be lovely to see more people do it. Should start getting people interested in the programme at the start of university.' (Student 3) 
As a final comment from students, we chose the summary provided by the only female interviewee about her industrial experience:

'Completing a year in industry has improved my technical knowledge for university in preparation for my third and fourth years, it has also helped me with my personal skills for career - going forward. These are the two major things I want - this is how you can become a well-rounded person. In terms of grades I can get back to you in a couple of weeks - I believe I was a lot more confident in the exams and my thinking has completely changed. You become a lot more wide based because you have that year in industry to broaden your horizons. It shows you the avenues of work that you like and the avenues of work that you don't like. It was good to know that I never want to go into that direction. Following [industrial experience] I was offered a summer placement with [the same company] working for an R\&D team and that was brilliant. But I know I don't want to work for an $R \& D$ team. A couple of weeks ago I received a job offer so it has been a very successful year.'

\section{Discussion/Conclusion}

Students' perceptions about the WIE programme and their experience of it have been detailed and reported, largely in their own words. We believe that the way forward is to take into account their experiences, and constructively improve the programme based on their feedback.

What could also be useful, and is missing from this analysis, in order to assess the effectiveness of the programme in improving students' learning outcomes, is to quantitatively measure change (if any) and compare with students not choosing the course. However, we also believe that attitudinal measures are also important to inform change and should be used by HE leaders and academics to inform good practice in curriculum development.

Some ideas are already in place for change and in order to increase the numbers of students who could benefit from such programmes a 2-day career development event for second-year students and a larger, more diverse careers fair within the School have already been tested. We have also attempted to get students closer to industrial partners via events such as 'Meet the engineers' supported by the Institute of Engineering and Technology (IET). Future streamlining of the programme with a working committee to oversee the process is also given.

\section{References}

1 N. Powell et al., 'Four case studies of adapting enquiry-based learning (EBL) in electrical and electronic engineering', Int. J. Elect. Enging Educ., 45(2) (2008), 121-130.

2 J. E. Mills and D. F. Treagust, 'Engineering Education - is problem-based or project-based learning the answer?' Australasian J. Eng. Educ., (2003), 1-16, available online at http://www.aaee.com.au/ journal/2003/mills_treagust03.pdf, last accessed 16 April 2013.

3 G. Ryan, S. Toohey and C. Hughes, 'The purpose, value and structure of the practicum in higher education: a literature review,' Higher Educ., 31 (1996), 355-377. 
4 R. Mendez and A. Rona, 'The relationships between industrial placements and final degree results: a study of engineering placement students', Learning and Teaching in Higher Education, 4(2) (2010), 46-61.

5 N. L. Driffield, C. S. Foster and H. E. Higson, 'Placements and degree performance: Do placements lead to better marks, or do better students choose placements?', in Proc. ASET Annual Conference, Leeds, 2011.

6 Y. N. AuYeung et al., 'Attitudes towards industrial training in the BEng. course in building services engineering at Hong Kong Polytechnic', Studies in Higher Education, 18(2) (1993), 205-226.

7 G. Lock et al., 'Exploring the industrial placement experience for mechanical engineering undergraduates', Eng. Educ., 4(1) (2009), 42-51.

8 F. Trede, 'Role of work-integrated learning in developing professionalism and professional identity', Asia-Pacific J. Coop. Educ., 13(3) (2012), 159-167.

9 S. M. Vaezi-Nejad, 'Work placement for professional experience in electronics and communications engineering education', Int. J. Elect. Enging Educ., 46(3) (2009), 280-294. 